Check for updates

Cite this: RSC Adv., 2017, 7, 27441

\title{
Experimental study of a passive thermal management system for three types of battery using copper foam saturated with phase change materials
}

\author{
Ziyuan Wang, ${ }^{a}$ Xinxi Li, (DD *a Guoqing Zhang, ${ }^{a}$ Youfu Lv, ${ }^{a}$ Jieshan He, ${ }^{a}$ Jinghai Luo, ${ }^{a}$ \\ Chengzhao Yang ${ }^{\mathrm{b}}$ and Chuxiong Yang ${ }^{\mathrm{b}}$
}

Battery thermal management (BTM) technology is vital for the development of new energy vehicle because the lithium batteries exhibit a more resistive behavior leading to extra heat generation with age. The CF/PCM (copper foam/phase change material) coupled thermal management system for different types of lithium ion batteries such as 26650, 42110 and square $(105 \mathrm{~mm} \times 28 \mathrm{~mm} \times 71 \mathrm{~mm})$ were selected comparatively to research in detail, especially at a relatively high discharge rate. To evaluate the effect of the battery generating heat close to the actual operating conditions, the thermal management system in an insulated environment were investigated at discharge rate of $5 \mathrm{C}$, in comparison with a natural convection environment. Furthermore, the results show that the effect of the temperature control based PCM is improved when compared to air-based BTM under an insulated environment. Moreover, the maximum temperature of 26650, 42110 and square batteries of CF/PCM coupled with BTM can be controlled below $44.37{ }^{\circ} \mathrm{C}, 51.45^{\circ} \mathrm{C}$ and $50.69^{\circ} \mathrm{C}$ for a longer time than those of the pure PCM based case and air-based case under the same conditions, respectively. The passive system was coupled with copper foam as a skeleton net structure to improve the strength of the PCM during its melting. More importantly, a CF/PCM (copper foam/phase change material) battery thermal management system was designed and tested experimentally.

Received 7th April 2017

Accepted 8th May 2017

DOI: $10.1039 / c 7 r a 03963 h$

rsc.li/rsc-advances

\section{Introduction}

Li-ion batteries are considered the most promising candidates for hybrid electric vehicles (HEV) and electric vehicles (EV). ${ }^{1}$ The high gravimetric and volumetric energy density of Li-ion batteries provide enough advantages over other battery chemistries, such as lead acid and NiMH. However, challenges have arisen from their active material and electrolyte, which impede their application and thermal imbalance leads to heterogeneities of aging and state of charge due to the chemical behavior of the battery. ${ }^{2,3}$ The thermal runaway of lithium ion batteries can give rise to safety risks such as overheating, combustion and even explosion, which further destroy the charge-discharge performance and lifespan. ${ }^{4,5}$

Different types of Li-ion batteries have similar drawbacks such as overheating and related safety problems that serious limits their applications. During the operating process of batteries as the current flows through the internal resistance, heat is consistently generated. Along with the battery operating,

${ }^{a}$ School of Materials and Energy, Guangdong University of Technology, Guangzhou 510006, China.E-mail: pkdlxx@163.com

${ }^{b}$ Guangdong Markham Technology Co. Ltd, Shunde 528322, China ohmic heating as main heat sources would affect the safety of battery. ${ }^{6}$ In addition to the mentioned thermal behavior of batteries, the chemical reaction during the charging and discharging process can contribute to overheating, especially at a high discharge rate. However, if the overheating of batteries is not dissipated immediately, thermal runaway will cause the catastrophic destruction of the batteries. ${ }^{7}$ Thus, it is important to investigate the battery thermal performance, especially at a high discharge rate.

In most instances, researchers have paid a lot of attention towards the battery performance under ambient temperature. Whereas, in general, battery packs have to be encapsulated in a sealed box rather than exposed to air when applied in different electric vehicles. ${ }^{8}$ In order to approximate the actual application conditions, the charge and discharge performance of batteries needs to be investigated under insulated conditions. As we all known, the thermal runaway of batteries under heat insulates condition will become more serious. ${ }^{9}$ Therefore, it is necessary to enforce temperature control for all kinds of batteries, improve their safety performance and even enhance its cycle life. Confronted with thermal hazards under different circumstances, a robust battery thermal management (BTM) is essential to protect the battery. 
Recently, most EVs have air-cooling BTMs, however, they present many more drawbacks, such as fan power, which depletes the battery energy and induce to a large thermal imbalance between the downstream batteries. ${ }^{10-12}$ Wang has researched forced air cooling strategies using a numeric simulation method among the different arrangement structures in cylindrical battery packs and the results showed just a few advantages to BTM. ${ }^{13}$ Mahamud and Park presented a novel reciprocating air cooling style, which can maintain a uniform temperature and proposed the improved lumped-capacitance thermal model and flow network model. ${ }^{\mathbf{4}}$ Moreover, Liang et al. investigated the structural design and optimization of reciprocating ventilation used for battery thermal management. Different types of cooling styles, such as heat pipes, can be provided by the battery liquid cooling systems. ${ }^{15,16} \mathrm{Y}$. Ye et al. provided both the cooling and heating performance of an EV battery controlled by heat pipes. ${ }^{17}$ Tran et al. considered the cooling performance of heat pipes for hybrid electric vehicles/ electric vehicles using Li-ion battery thermal management experimentally. ${ }^{\mathbf{1 8}}$

On the whole, the BTM methods, such as air cooling and liquid cooling systems, have been extensively researched and adopted for commercial applications. However, the components of the heat dissipation methods, such as fans and pumps, are generally complicated, bulky and power-wasting, which can diminish the limited energy stored in the batteries. Meanwhile, many others BTMs are also listed in the literature and each of them presents disadvantages, such as difficult sustainment, expensive integration or limited effectiveness in terms of their thermal uniformity. ${ }^{19-21}$ These undesirable disadvantages provoke expectations for novel thermal management systems.

Related to the above mentioned methods of battery thermal management, PCM-based cooling systems seem to be a suitable method due to the relatively constant temperature of the phase transition. PCMs have many advantages, such as high energy efficiency, high compactness and low maintenance cost, which have drawn great attention as passive thermal management in application. ${ }^{22-24} \mathrm{Al}-\mathrm{Hallaj}$ et al. first proposed the application of PCMs to battery thermal management systems and the heat generated inside the batteries could be absorbed by the PCM with a large latent heat to keep the temperature within the safe range for a long time in the battery pack. ${ }^{25}$ Duan et al. researched the thermal management system of a cylindrical battery monomer with a PCM cylinder and with PCM jackets, respectively. The measurements showed the systems to be highly effective in controlling the temperature. ${ }^{26}$ Zhang et al. researched the battery thermal management performance and the thermal energy storage properties using paraffin as the PCM, the results showed the thermal energy storage was improved to a certain extent. ${ }^{27}$ Rao et al. applied a numerical simulation on commercial rectangular $\mathrm{LiFePO}_{4}$ batteries with a PCM and obtained the conclusion that is was essential to have an appropriate proportion of thermal conductivities within the passive thermal management system. ${ }^{28}$ Nevertheless, the thermal performance of low conductivity restricts the use of PCM-based cooling systems in application and subsequently, thermal composites were proposed. Khateeb et al. proposed a battery module comprised of eighteen 18650-type cells wrapped by a PCM with Al-foam for an electric scooter. The test results exhibited the utilization of avPCM with foam metal was an effective method to improve the battery's thermal performance. In adition, they designed experiments to validate the PCM with Al-foam model, the measurements showed Al-foam with PCM could decrease the increase in battery temperature by $50 \%$ relative to the battery without passive thermal management. ${ }^{29,30}$ Wang et al. investigated the thermal behavior of a cylindrical battery with a composite paraffin and fin structure, and showed the enhanced properties of the composite structure when compared to the pure PCM. ${ }^{31}$ Many similar works related to PCM and BTMs have been reported recently, ${ }^{32-35}$ however, few studies have investigated the composite method of improving the strength and thermal performance of PCMs for batteries, especially for the different types of Li-ion batteries.

In this research, in order to improve the strength and capability of heat transfer in the BTM system, copper foam as a metal skeleton structure with pure PCMs was adopted. Three different types of battery including 26650, 42110 and square were examined experimentally under different conditions, operated under different discharge rates, especially at 5C. In order to research the battery under a working environment, the experiment was designed and carried out as follows: firstly, the temperature of the battery was compared among the three different types of batteries at different discharge rates in a natural convection environment. Then, the temperature of the battery's surface was compared at relatively high discharge rate conditions between the insulated and natural convection environments. Eventually, the thermal performance using pure paraffin and CF/PCM, respectively under an insulated environment was investigated.

\section{Experimental}

The $x, y, z$ rectangular coordinates of battery heat flux can be shown as follows, on the basis of the complex characteristics of its orthotropic materials while charging or discharging.

$$
\begin{aligned}
& q_{x}=-\lambda_{x x} \frac{\partial T}{\partial x}-\lambda_{x y} \frac{\partial T}{\partial y}-\lambda_{x z} \frac{\partial T}{\partial z} \\
& q_{y}=-\lambda_{y x} \frac{\partial T}{\partial x}-\lambda_{y y} \frac{\partial T}{\partial y}-\lambda_{y z} \frac{\partial T}{\partial z} \\
& q_{z}=-\lambda_{z x} \frac{\partial T}{\partial x}-\lambda_{z y} \frac{\partial T}{\partial y}-\lambda_{z z} \frac{\partial T}{\partial z}
\end{aligned}
$$

A classical mathematical description of a two-dimensional steady-state and incompressible fluid was used to describe the heat convection process and heat dissipation of the battery module.

Equation of conservation of mass 


$$
\frac{\partial u}{\partial x}+\frac{\partial v}{\partial y}=0
$$

Equation of conservation of momentum

$$
\begin{aligned}
& \rho\left(u \frac{\partial u}{\partial x}+v \frac{\partial v}{\partial y}\right)=F_{x}-\frac{\partial P}{\partial x}+\mu\left(\frac{\partial^{2} u}{\partial x^{2}}+\frac{\partial^{2} u}{\partial y^{2}}\right) \\
& \rho\left(u \frac{\partial v}{\partial x}+v \frac{\partial u}{\partial y}\right)=F_{y}-\frac{\partial P}{\partial y}+\mu\left(\frac{\partial^{2} v}{\partial x^{2}}+\frac{\partial^{2} v}{\partial y^{2}}\right)
\end{aligned}
$$

Equation of conservation of energy

$$
\rho C_{\mathrm{p}}\left(u \frac{\partial T}{\partial x}+v \frac{\partial T}{\partial y}\right)=\lambda\left(\frac{\partial^{2} T}{\partial x^{2}}+\frac{\partial^{2} T}{\partial y^{2}}\right)
$$

Equation of convective heat transfer equation

$$
h=-\frac{\lambda}{T_{w}-T_{f}} \frac{\partial T}{\partial y}
$$

In the battery thermal management system, the mass of the PCM required was calculated as follows

$$
M_{\mathrm{PCM}}=\frac{Q_{\mathrm{dis}}}{C_{\mathrm{p}}\left(T_{\mathrm{m}}-T_{\mathrm{i}}\right)+H}
$$

Assuming a binary electrolyte and neglecting the enthalpy of mixing and phase change effects, the heat generation over all the reactions term can be expressed as follows ${ }^{36}$

$$
\begin{aligned}
q= & \sum_{j} \alpha_{\mathrm{s} j} i_{\mathrm{n} j}\left(\varphi_{\mathrm{s}}-\varphi_{\mathrm{e}}-U_{j}\right)+\sum_{j} \alpha_{\mathrm{s} j} i_{\mathrm{n} j} T \frac{\partial U_{j}}{\partial T}+\sigma^{\mathrm{eff}} \nabla \varphi_{\mathrm{s}} \nabla \varphi_{\mathrm{s}} \\
& +\kappa^{\mathrm{eff}} \nabla \varphi_{\mathrm{e}} \nabla \varphi_{\mathrm{e}}+\kappa_{\mathrm{D}}^{e f f} \nabla \ln c_{\mathrm{e}} \nabla \varphi_{\mathrm{e}}
\end{aligned}
$$

The 26650, 42110 and square size $(105 \mathrm{~mm} \times 28 \mathrm{~mm} \times 71$ $\mathrm{mm}$ ) types of lithium iron phosphate power batteries were selected and the battery parameters are displayed in Table 1. For the purpose of investigating the heat production behavior of the batteries, different rates of discharge were operated under ambient conditions. According to the previously reported results, the total heat production of batteries can be estimated from the basic theoretical knowledge of engineering thermodynamics, heat transfer theory and hydromechanics. Moreover, the insulated conditions were designed and a copper foam/ phase change material (CF/PCM) applied in the experiment. A schematic diagram of the battery thermal experiment is shown in Fig. 1.

In this research, the BTM method was investigated using the composites with copper foam and phase change material $(\mathrm{CF} /$ PCM). Copper foam was used as a thermal conductive skel-

\begin{tabular}{|c|c|c|c|c|c|}
\hline Types & $\begin{array}{l}\text { Capacity } \\
(\mathrm{mA} \mathrm{h})\end{array}$ & Voltage (V) & Quality (g) & $\begin{array}{l}\text { Resistance } \\
(\mathrm{m} \Omega)\end{array}$ & $\begin{array}{l}\text { Cut-off voltage } \\
\text { (V) }\end{array}$ \\
\hline 42110 & 10000 & 3.2 & 188 & 9.35 & 3.7 \\
\hline 26650 & 3000 & 3.2 & 89 & 15.33 & 3.65 \\
\hline Square & 10000 & 3.2 & 387 & 10.75 & 3.7 \\
\hline
\end{tabular}
eton whose porous structure can be filled with the melting state of the PCM to improve the heat-transfer capability. The copper foam was $5 \mathrm{~mm}$ thick with a surface density of $2000 \mathrm{~g} \mathrm{~m}^{-2}$ and volume density of $0.4 \mathrm{~g} \mathrm{~cm}^{-3}$. The PCM adopted was refined paraffin whose melting range was $45^{\circ} \mathrm{C}$ to $47^{\circ} \mathrm{C}$. The PCM used
Table 1 The parameters of the three different types of lithium ion power battery

for the battery thermal management system can maintain the temperature steady in its phase change range through absorbing heat from the batteries during charging or discharging process, for the purpose of balancing the temperature of the battery pack. At a discharge rate of $5 \mathrm{C}$, the heat produced by battery with the copper foam and paraffin composite was calculated and the three different types of battery were measured. Before starting the experiments, the batteries were placed in the thermostat for $12 \mathrm{~h}$ to achieve a uniform temperature and stability among the different batteries. The three types of battery studied included 26650, 42110 and square battery and were investigated at a discharge rate of $5 \mathrm{C}$.

\section{Results and discussion}

In this study, the results are presented in three parts. The first part describes the comparison of the temperature of the battery surface among the three different types of battery $(26650,42110$ and square) at different discharge rates in a natural convection environment. The second part describes the comparison of the temperature of the battery surface at a discharge rate of $5 \mathrm{C}$ between the insulated and natural convection environments. The last part describes how the thermal performance of the batteries is affect by pure paraffin and the CF/PCM, respectively under an insulated environment.

\subsection{A comparison of the temperature response among the different types of lithium ion batteries at different discharge rates under a natural convection environment}

The test results of the 26650 battery at different discharge rates under a natural convection environment are shown in Fig. 2a. The surface temperature of the battery was $34.7^{\circ} \mathrm{C}, 41.68^{\circ} \mathrm{C}$ and $62.77^{\circ} \mathrm{C}$ at a discharge rate of $1 \mathrm{C}, 3 \mathrm{C}$ and $5 \mathrm{C}$, respectively. It is notable that the largest temperature rise reached $83.9 \%$ at a discharge rate of $5 \mathrm{C}$ and the span of time maintain $365 \mathrm{~s}$ under $55{ }^{\circ} \mathrm{C}$. We may draw a conclusion that the temperature rise was seriously affected by the rate of discharge. The higher discharge rate is accompanied by an increase in temperature and the heat production of the battery increases. In order to verify the reliability of the conclusion, the 42110 and square battery were investigated under the same conditions and the results are shown in Fig. $2 \mathrm{~b}$ and $\mathrm{c}$. The maximum temperature of the battery surface was much higher at the higher discharge rate, as shown in Fig. 2d. The heat production was also much higher, which would bring potential safety risks in the application of the battery. The details of the temperature difference ratio at certain times are presented in Table 2 . It was necessary 


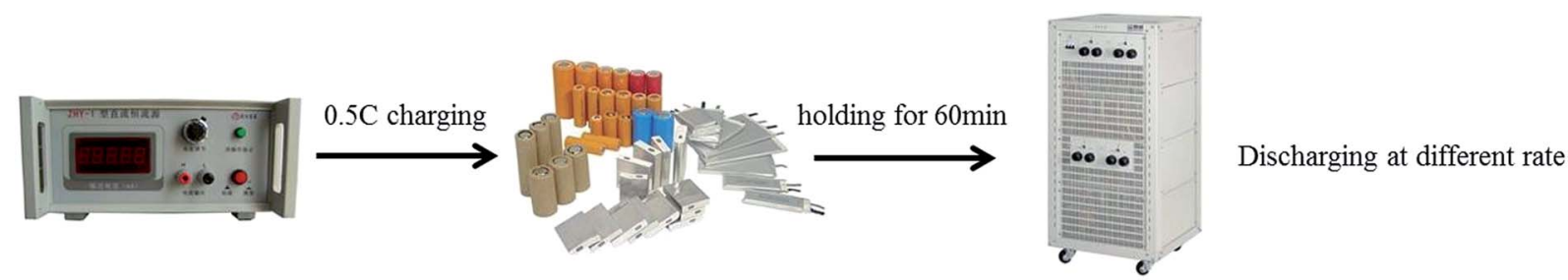

\section{Constant Current Source (CCS)}

Batteries

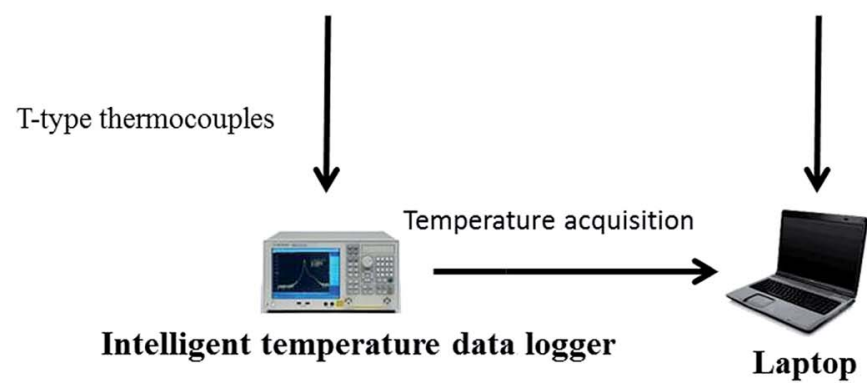

Data collection and heat production assessment

Fig. 1 A schematic representation of the thermal response measurement platform used for batteries.

to investigate the battery performance at a higher discharge rate.

\subsection{The differences in the battery temperature under the insulated and natural convection environments}

Considering the negative effects of high temperatures on the safety of the batteries, the temperature differences among the three types of battery (26650, 42110 and square battery) at a discharge rate of $5 \mathrm{C}$ were investigated. To simulate the actual working conditions of batteries, the battery was positioned in a stainless steel chamber to insulate the battery from the surrounding environment, which had no exchange of energy and quality, and the heat generated by the battery is not dissipated through heat radiation and convection.
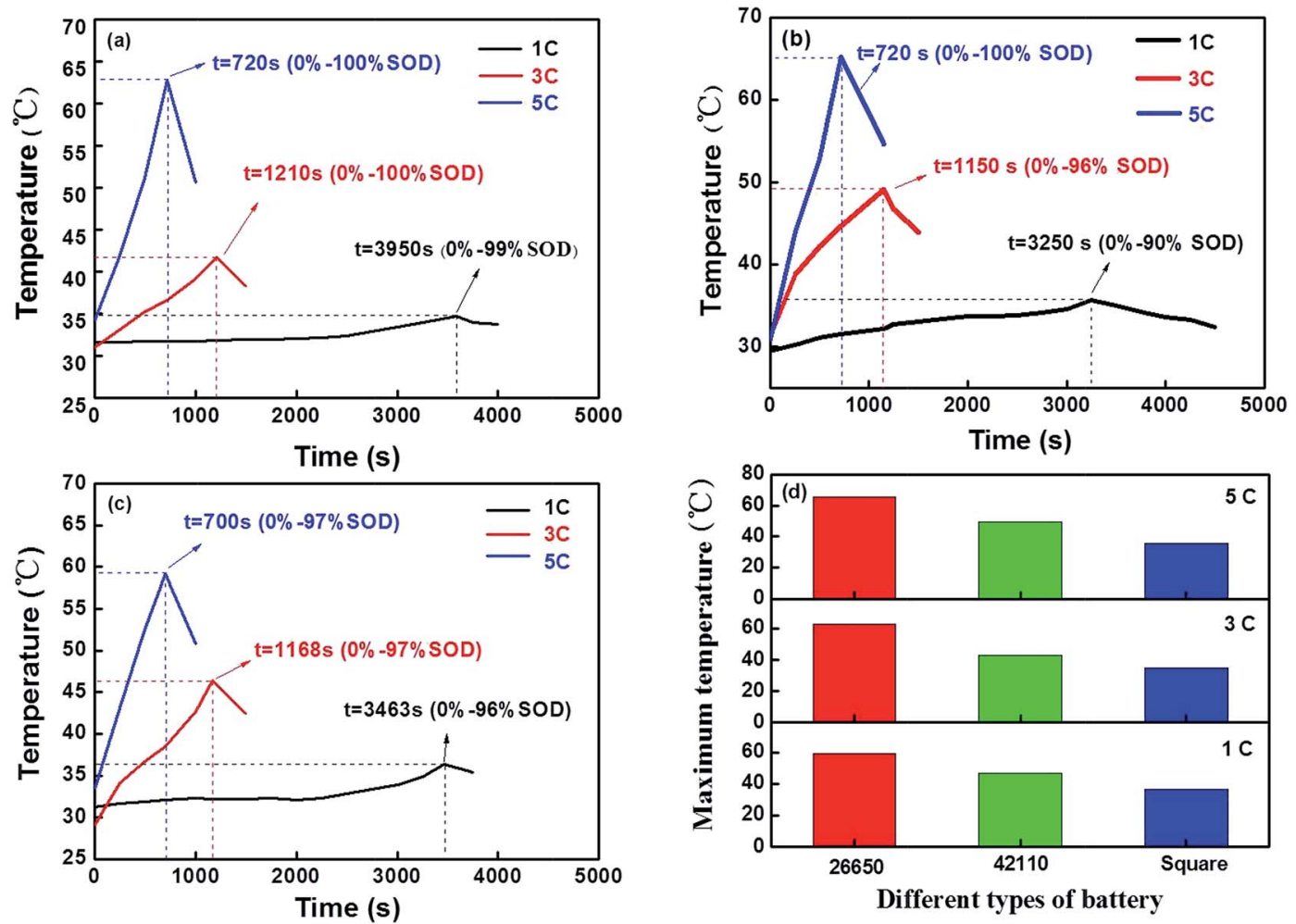

Fig. 2 The temperature of the batteries at different discharge rates in a natural convection environment: (a) 26650, (b) 42110, (c) square battery and (d) maximum temperature for the different types of battery. 
Table 2 The percentage temperature rise and heat production value observed for the three types of battery at different discharge rates

\begin{tabular}{lllrlrr}
\hline Types & 1C (\%) & 3C (\%) & 5C (\%) & 1C (J) & 3C (J) & 5C (J) \\
\hline 26650 & 10.0 & 34.9 & 83.9 & 1183 & 2802 & 4545 \\
42110 & 21.2 & 56.7 & 107.0 & 1821 & 5925 & 10247 \\
Square & 16.3 & 59.7 & 77.5 & 1688 & 7005 & 16927
\end{tabular}

The experimental results obtained for the 26650, 42110 and square batteries under the natural convection and insulated environments are displayed in Fig. 3a-c. The results show that the temperature increase of the battery under an insulated environment was at least $10 \%$ higher than under a natural convection environment at a discharge rate of $5 \mathrm{C}$. The temperature reached a peak in the curve and then decreased, which was attributed to the battery running out of energy. At the same time, this tendency observed for the temperature in the battery under an insulated environment was slower than in the natural convection environment. The above factors show that the test under an insulated environment can be considered as a study on a heat insulation condition system of the battery module in an electric automobile. The maximum temperature of the battery surface in the different types of battery are shown in Fig. 3d. The heat value and temperature rise under an insulated environment for the three types of battery were higher than under a natural convection environment. Considering the above-mentioned test results, it is very necessary to research the (a)

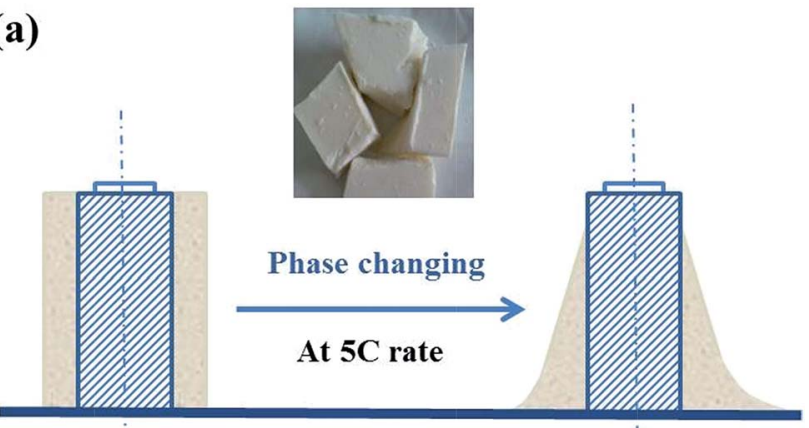

(b)

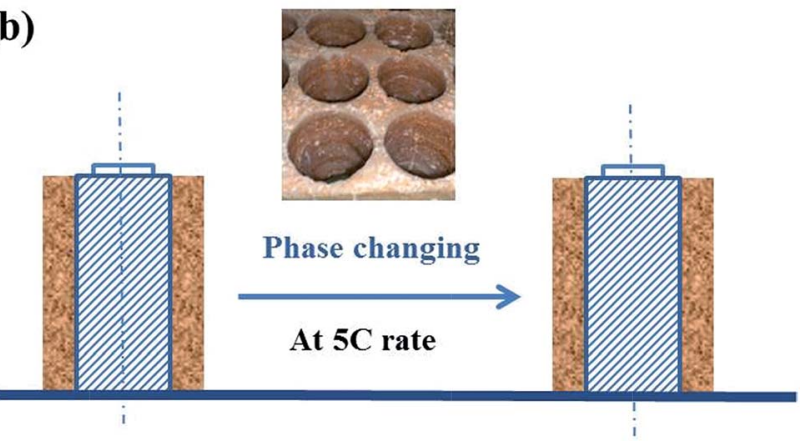

Fig. 4 A comparison of the battery between paraffin and CF/PCM for thermal management: (a) pure paraffin and (b) CF/PCM.

battery performance under an insulated environment to alleviate the potential safety hazards in their applications, such as in electric automobiles.
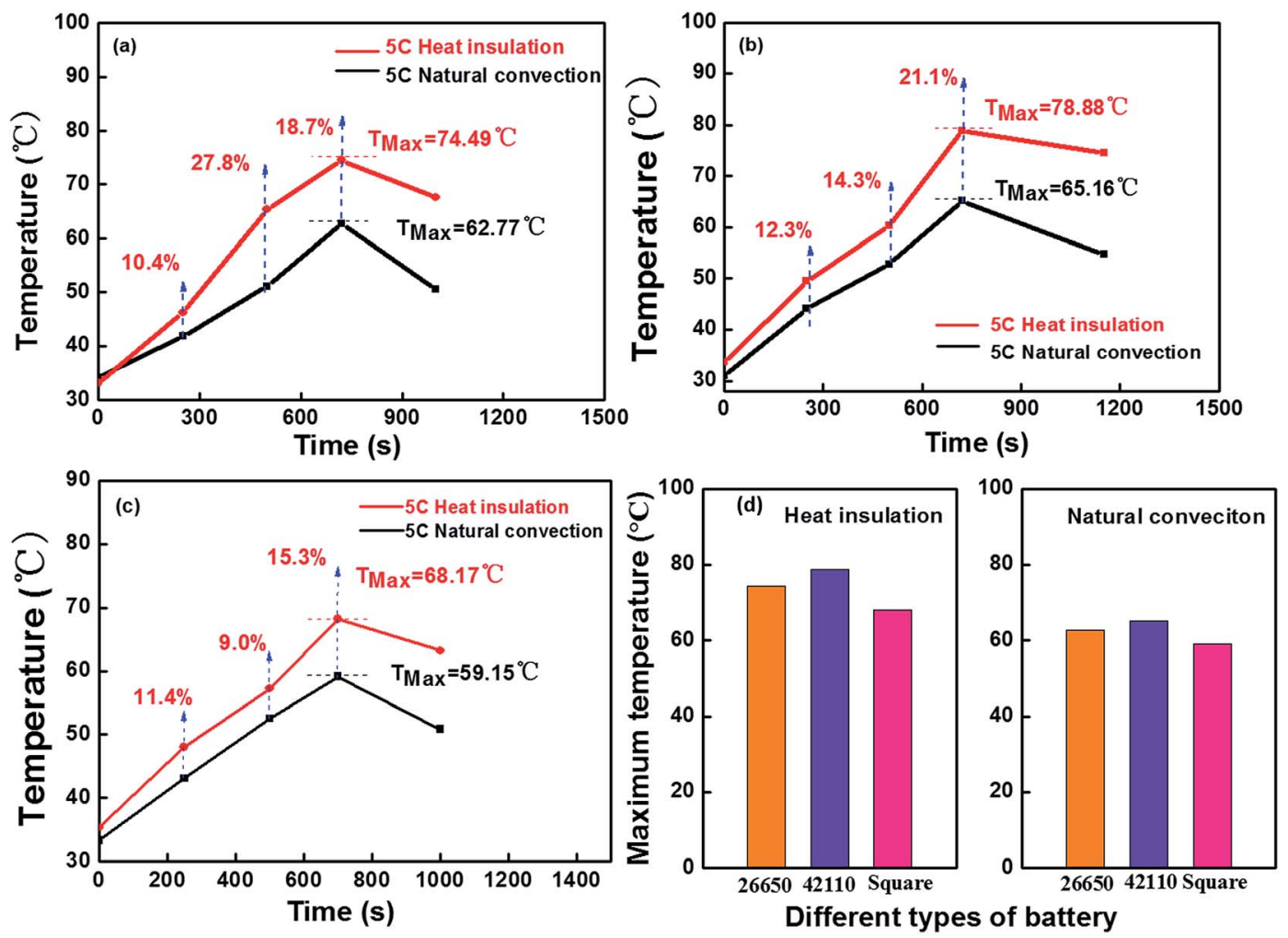

Fig. 3 A comparison of the temperature of the batteries at a discharge rate of 5C under the different environments: (a) 26650, (b) 42110, (c) square battery and (d) maximum temperature for the different types of battery. 


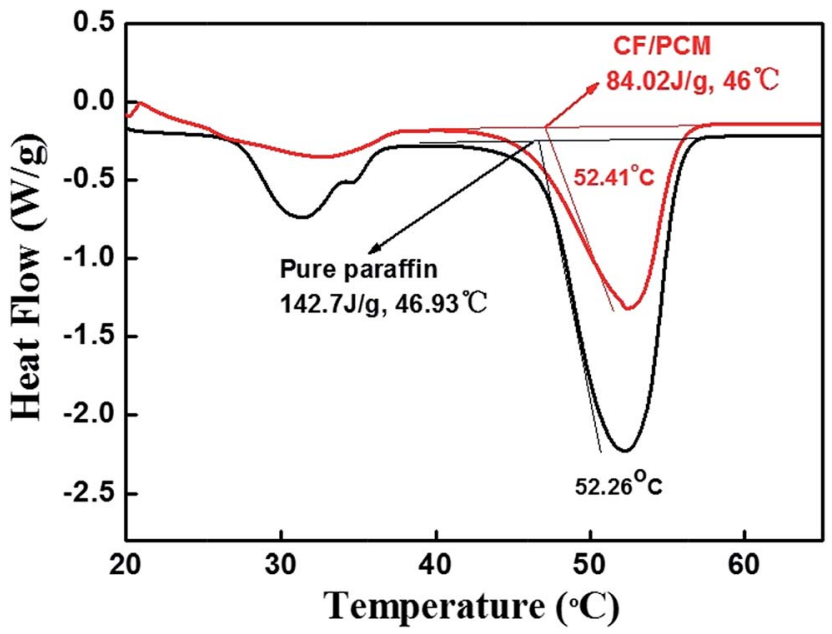

Fig. 5 The typical DSC curves obtained for pure paraffin and CF/PCM.

3.3 A comparison of the temperature response between the batteries with pure paraffin and CF/PCM during a mixed charge-discharging process

Under high discharge rates, the temperature of the 26650, 42110 and square battery were all over the optimal $45^{\circ} \mathrm{C}$, in which the heat is dissipated with difficulty and increases the temperature rapidly. When battery temperature was out of control after a long enough time, there would be a serious safety threat to the electrochemical performance and cycle life of the lithium ion battery. What's more, it's necessary to study an efficient thermal management system for the different types of lithium ion battery.

To evaluate the cooling effect of the passive thermal management on the module, a mixed charge-discharge cycle was used. During the cycle procedure, the battery was initially charged in constant current mode at a rate of $0.5 \mathrm{C}$ with a terminal cut-off voltage and then charged at a constant voltage until the current dropped to $0.1 \mathrm{~A}$. After holding for $60 \mathrm{~min}$, the battery was then discharged in constant current mode at a rate of $5 \mathrm{C}$ until the terminal voltage reached the cut-off. The last step of the cycle was a resting period of $60 \mathrm{~min}$. In this section, firstly, the schematic diagram of the battery under the insulated environment was analyzed, which mainly introduced the difference between the pure paraffin and CF/PCM for dissipating heat in battery. Then, the different types of battery (26650, 42110 and square) were selected to investigate the temperature differences among the insulated environment, pure paraffin and CF/PCM conditions for thermal management.
Meanwhile, the maximum temperatures of the three types of battery were compared to illustrate the importance of battery thermal management.

During the discharge process at $5 \mathrm{C}$, the heat production of the battery could improve the temperature on the battery surface and then, the pure paraffin wrapped around the battery would melt and become flow statues, which would make the heat dissipation of the battery unstable and bring about huge potential safety hazard. A schematic diagram was shown in Fig. 4a. Confronted with such issues, in Fig. 4b, the copper foam was considered to improve the stability of the PCM as a thermal conductive skeleton whose porous structure will be filled by the melting state of the PCM to improve the heat-transfer capability. In otherwords, the copper foam not only improves the stability of the PCM, avoiding it flowing while absorbing the heat from the battery, but also strengthens the heat transfer capability of the battery.

The latent heats of the phase change were determined by numerical integration of the area under the peaks in Fig. 5. The latent heats of melting were found to be $142.7 \mathrm{~J} \mathrm{~g}^{-1}$ and $84.02 \mathrm{~J}$ $\mathrm{g}^{-1}$ for the pure paraffin and $\mathrm{CF} / \mathrm{PCM}$, respectively. What's more, the peak of heat flow of pure paraffin was larger than $\mathrm{CF}$ / PCM. The main reason could be attributed to CF/PCM having less liquidity and a more stable performance than pure paraffin while absorbing heat, though it has a lower phase change enthalpy than the pure paraffin, which is beneficial for battery thermal management applications.

The qualities of the copper foam and paraffin in the three types of battery are presented in Table 3. The percentage of paraffin surrounding the integrity of the battery has an important role to dissipate its heat production. In Fig. 6, the temperature of the 26650,42110 , square types of battery along with the discharge time, respectively are shown in order to clearly illustrate the temperature variation regularity; the value of $K$ was taken as s, the slope of the splashes after linear fitting. The measurement results, which were $K_{3}<K_{2}<K_{1}$, reveal the battery thermal management with PCM (pure paraffin and $\mathrm{CF}$ / PCM) was beneficial to the progress of the electrochemical reaction and moreover, the battery thermal management with CF/PCM could improve the thermal performance. This was attributed to the copper foam strengthening the PCM when it absorbs or dissipates heat. Meanwhile, the maximum of the temperature of three types of battery are shown in Fig. 6d. Whatever the type of the battery, when wrapped with the $\mathrm{CF}$ / PCM they displayed a lower temperature than the others. When the battery temperature reached the phase change range, paraffin would absorb lots of heat produced by the battery in order to keep the battery temperature balance in the safe range.

Table 3 The qualities and percentages of paraffin and copper foam in the different types of battery

\begin{tabular}{lllll}
\hline Types & $\begin{array}{l}\text { The quality } \\
\text { of paraffin }(\mathrm{g})\end{array}$ & $\begin{array}{l}\text { The quality of } \\
\text { copper foam }(\mathrm{g})\end{array}$ & $\begin{array}{l}\text { The percentage } \\
\text { of paraffin }(\%)\end{array}$ & $\begin{array}{l}\text { The percentage } \\
\text { of copper foam }(\%)\end{array}$ \\
\hline 26650 & 13.34 & 6.77 & 66.34 & 33.66 \\
42110 & 31.24 & 15.39 & 67.0 & 33.0 \\
Square & 51.60 & 25.41 & 67.01 & 32.99
\end{tabular}



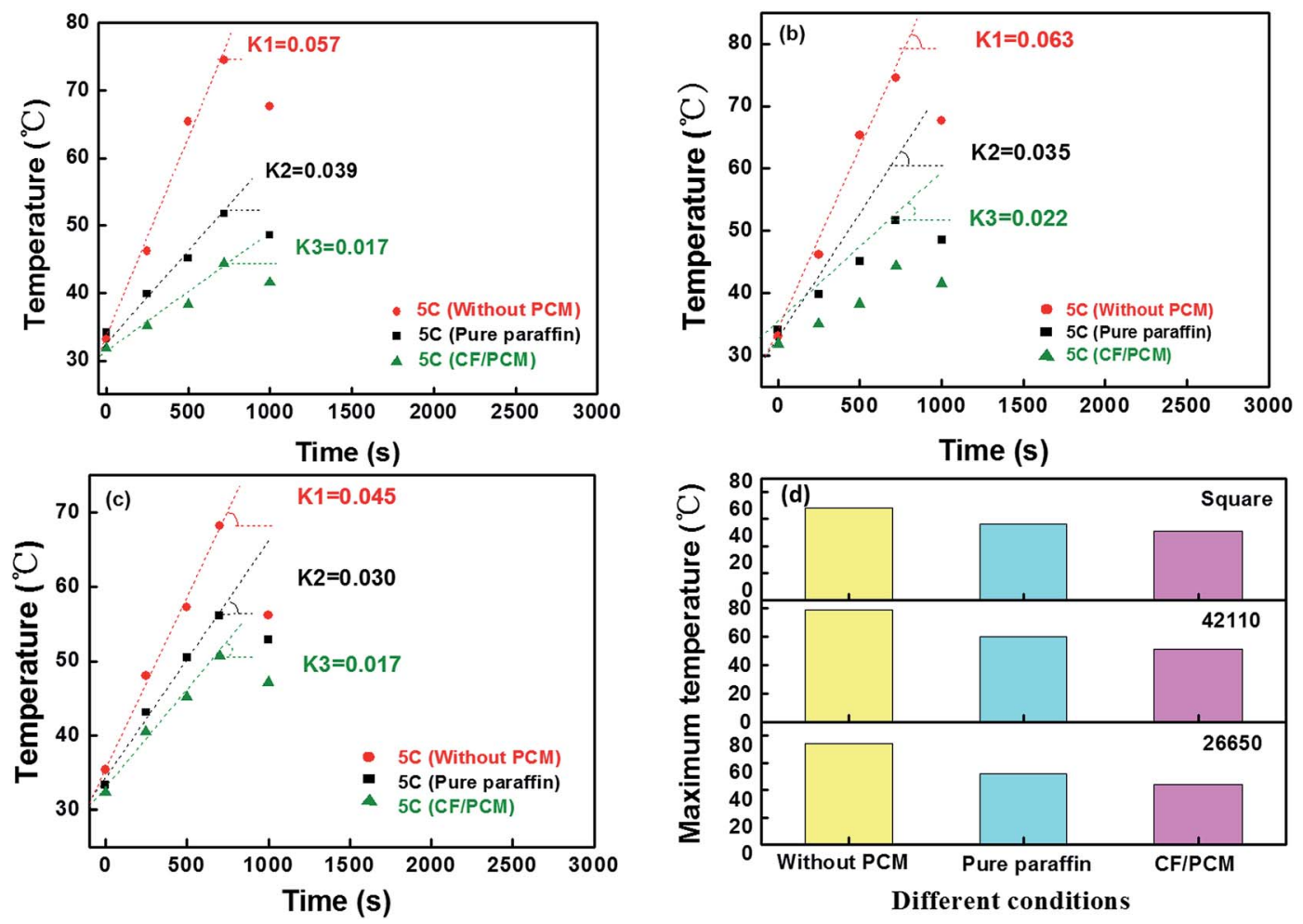

Fig. 6 A comparison of the temperature of the batteries at a discharge rate of 5C: (a) 26650, (b) 42110, (c) square battery and (d) maximum temperature for the different types of battery under the different conditions.

At the same time, the heat transfers to the copper foam, which can rapidly dissipate and make temperature distribution equal because of its high thermal conductivity. Moreover, the network skeleton of the copper foam can repair the paraffin while in the process of absorbing or dissipating heat. Therefore, the $\mathrm{CF} / \mathrm{PCM}$ can effectively improve the thermal performance of the battery under an insulated environment.

\section{Conclusions}

In order to research the performance of a $\mathrm{CF} / \mathrm{PCM}$ coupled thermal management system for three types of selected battery (26650, 42110 and square), a CF/PCM based module under an insulated environment was designed. The value of the temperature rise and maximum temperature were examined experimentally and discussed under the different conditions in detail. The main conclusion could thus be summarized as follows:

(1) At different discharge rates, the heat production temperature of the 26650,42110 and square batteries were measured. The results showed the surface temperature of the 26650 battery was $34.7^{\circ} \mathrm{C}, 41.68^{\circ} \mathrm{C}$ and $62.77^{\circ} \mathrm{C}$ at a discharge rate of $1 \mathrm{C}, 3 \mathrm{C}$ and $5 \mathrm{C}$, respectively. The 42110 and square batteries have a similar tendency, which revealed that the different types of battery at a relatively high discharge rate will bring a similar potential safety risk in the application of the batteries. It is necessary to further investigate the battery performance at a discharge rate of $5 \mathrm{C}$.
(2) To evaluate the cooling effect of the battery close to actual working conditions, as a comparison with a natural convection environment, the thermal management system in an insulated environment was investigated at a discharge rate of $5 \mathrm{C}$. The results showed that the temperature rise in the insulated environment observed for the three types of battery were higher than under a natural convection environment. Thus it is essential to research the battery performance under an insulated environment to alleviate the potential safety hazards in their applications, such as in electric automobiles.

(3) The effect of the temperature control based PCM was improved when compared to air-based BTM under an insulated environment at a discharge rate of 5C. Moreover, the maximum temperature of the 26650, 42110 and square batteries with a $\mathrm{CF} /$ PCM coupled BTM could be controlled to below $44.37{ }^{\circ} \mathrm{C}$, $51.45^{\circ} \mathrm{C}$ and $50.69^{\circ} \mathrm{C}$, respectively, for a longer time than those of the pure PCM-based and air-based BTMs. The most important improvement, the passive system was coupled with copper foam as a three dimensional skeleton to improve the strength of the PCM during its melting.

\section{Nomenclature}

$q_{x} \quad$ Heat flux in $x$ dimension $\left(\mathrm{J} \mathrm{m}^{-2} \mathrm{~s}^{-1}\right)$

$q_{y} \quad$ Heat flux in $y$ dimension $\left(\mathrm{J} \mathrm{m}^{-2} \mathrm{~s}^{-1}\right)$

$q_{z} \quad$ Heat flux in $z$ dimension $\left(\mathrm{J} \mathrm{m}^{-2} \mathrm{~s}^{-1}\right)$

$\lambda_{x x} \quad$ Thermal conductivity in $x$ dimension $\left(\mathrm{W} \mathrm{m}^{-1} \mathrm{~K}^{-1}\right)$

$\lambda_{x y} \quad$ Thermal conductivity in $x-y$ dimension $\left(\mathrm{W} \mathrm{m}^{-1} \mathrm{~K}^{-1}\right)$ 
$\lambda_{x z}$ Thermal conductivity in $x-z$ dimension $\left(\mathrm{W} \mathrm{m}{ }^{-1} \mathrm{~K}^{-1}\right)$

$T \quad$ Temperature (K)

$u \quad$ Velocity in $x$ dimension $\left(\mathrm{m} \mathrm{s}^{-1}\right)$

$v \quad$ Velocity in $y$ dimension $\left(\mathrm{m} \mathrm{s}^{-1}\right)$

$\alpha_{\mathrm{s} j} \quad$ Interfacial surface area per unit volume $\left(\mathrm{cm}^{2} \mathrm{~cm}^{-3}\right)$

$i_{\mathrm{n} j} \quad$ Transfer current density $\left(\mathrm{A} \mathrm{cm}^{-2}\right)$

$\mu \quad$ Velocity $\left(\mathrm{m} \mathrm{s}^{-1}\right)$

$h \quad$ Heat conductivity $\left(\mathrm{W} \mathrm{m}{ }^{-1} \mathrm{~K}^{-1}\right)$

$T_{\mathrm{w}} \quad$ The temperature of wall (K)

$T_{\mathrm{f}} \quad$ The temperature of fluid (K)

$\rho \quad$ Density $\left(\mathrm{kg} \mathrm{m}^{-3}\right)$

$C_{\mathrm{p}} \quad$ Specific heat capacity $\left(\mathrm{J} \mathrm{m}^{-3} \mathrm{~s}^{-1}\right)$

$K \quad$ Slope of splashes

$U_{\mathrm{j}} \quad$ Equilibrium potential (V)

$c_{\mathrm{e}} \quad$ Electrolyte $\left(\mathrm{mol} \mathrm{cm} \mathrm{cm}^{-3}\right)$

$\varphi_{\mathrm{e}} \quad$ Potential in the solution phase (V)

$\sigma^{\text {eff }} \quad$ Effective matrix conductivity $\left(\Omega^{-1} \mathrm{~cm}^{-1}\right)$

\section{Acknowledgements}

This work is supported by South Wisdom Valley Innovative Research Team Program (2015CXTD07), Scientific and Technological Project of Administration of Quality and Technology Supervision of Guangdong Province (2015PJ03) and Science and Technology Application Research and Development Projects of Guangdong Province, China (2015B010135010).

\section{References}

1 J. Jaguemont, L. Boulon and Y. Dubé, Appl. Energy, 2016, 164, 99-114.

2 S. Paul, C. Diegelmann, H. Kabza and W. Tillmetz, J. Power Sources, 2013, 239, 642-650.

3 F. Wu and Z. Rao, Appl. Therm. Eng., 2017.

4 K. Chen, X. Yu, C. Tian and J. Wang, Energy Convers. Manage., 2014, 77, 13-21.

5 P. Han, L. Lu, X. Qiu, Y. Tang and J. Wang, Energy, 2015, 91, 531-539.

6 R. Spotnitz and J. Franklin, J. Power Sources, 2003, 113, 81100.

7 B. Koo, P. Goli, A. V. Sumant, D. S. C. Pc, T. Rajh, C. S. Johnson, A. A. Balandin and E. V. Shevchenko, ACS Nano, 2014, 8, 7202-7207.

8 C. V. Hémery, F. Pra, J. F. Robin and P. Marty, J. Power Sources, 2014, 270, 349-358.

9 S. Wilke, B. Schweitzer, S. Khateeb and S. Al-Hallaj, J. Power Sources, 2017, 340, 51-59.

10 Z. Liu, Y. Wang, J. Zhang and Z. Liu, Appl. Therm. Eng., 2014, 66, 445-452.
11 H. Park, J. Power Sources, 2013, 239, 30-36.

12 J. Zhao, Z. Rao, Y. Huo, X. Liu and Y. Li, Appl. Therm. Eng., 2015, 85, 33-43.

13 T. Wang, K. J. Tseng, J. Zhao and Z. Wei, Appl. Energy, 2014, 134, 229-238.

14 R. Mahamud and C. Park, J. Power Sources, 2011, 196, 56855696.

15 Q. Wang, B. Jiang, Q. F. Xue, H. L. Sun, B. Li, H. M. Zou and Y. Y. Yan, Appl. Therm. Eng., 2014, 88, 54-60.

16 R. W. V. Gils, D. Danilov, P. H. L. Notten, M. F. M. Speetjens and H. Nijmeijer, Energy Convers. Manage., 2014, 79, 9-17.

17 Y. Ye, Y. Shi, L. H. Saw and A. A. O. Tay, Int. J. Heat Mass Transfer, 2016, 92, 893-903.

18 T. H. Tran, S. Harmand, B. Desmet and S. Filangi, Appl. Therm. Eng., 2014, 63, 551-558.

19 F. He, H. Wang and L. Ma, Int. J. Heat Mass Transfer, 2015, 91, 630-639.

20 Y. Ye, L. H. Saw, Y. Shi and A. A. O. Tay, Appl. Therm. Eng., 2015, 86, 281-291.

21 Z. Rao and S. Wang, Renewable Sustainable Energy Rev., 2011, 15, 4554-4571.

22 J. Zhao, P. Lv and Z. Rao, Exp. Therm. Fluid Sci., 2017, 82, 182-188.

23 Z. Rao, Q. Wang and C. Huang, Appl. Energy, 2016, 164, 659669.

24 W. Q. Li, Z. G. Qu, Y. L. He and Y. B. Tao, J. Power Sources, 2014, 255, 9-15.

25 R. Kizilel, R. Sabbah, J. R. Selman and S. Al-Hallaj, J. Power Sources, 2009, 194, 1105-1112.

26 X. Duan and G. F. Naterer, Int. J. Heat Mass Transfer, 2010, 53, 5176-5182.

27 Z. Wang, Z. Zhang, L. Jia and L. Yang, Appl. Therm. Eng., 2015, 78, 428-436.

28 Z. Rao, S. Wang and G. Zhang, Energy Convers. Manage., 2011, 52, 3408-3414.

29 S. A. Khateeb, M. M. Farid, J. R. Selman and S. Al-Hallaj, J. Power Sources, 2004, 128, 292-307.

30 S. A. Khateeb, S. Amiruddin, M. Farid, J. R. Selman and S. AlHallaj, J. Power Sources, 2005, 142, 345-353.

31 Z. Wang, H. Zhang and X. Xia, Int. J. Heat Mass Transfer, 2017, 109, 958-970.

32 Y. Huo and Z. Rao, Energy Convers. Manage., 2017, 133, 204215.

33 C. Liu and Z. Rao, Sci. Bull., 2017, 62, 231-233.

34 G. Jiang, J. Huang, M. Liu and M. Cao, Applied Thermal Engineering, 2017, 120, 1-9.

35 Q. Zhang, Y. Huo and Z. Rao, Sci. Bull., 2016, 61, 391-400.

36 Z. Rao, S. Wang, M. Wu, Z. Lin and F. Li, Energy Convers. Manage., 2013, 65, 92-97. 